\title{
Column
}

\section{Cultuur, welvaart en accountants}

\section{Hein Schreuder}

Er wordt tegenwoordig te weinig gepolemiseerd. Dat is de stellige overtuiging van sommige tijdschriftredacties, waarvan ik deel mag uitmaken. De ouderwetse polemiek is te zeer vervangen door het keurige citaat. Daarvan wordt wetenschap wel keurig, maar minder kleurig. En in ons soort wetenschap is de kleurstelling vrijwel nooit zwart-wit.

In het septembernummer van dit blad waren interessante beschouwingen te vinden over de relatie(s) tussen cultuur en accounting. Bahlmann besprak de consequenties van cultuurverschillen voor de beoordeling van prestaties. Van Hulle en Van der Tas EG-aliseerden het pad der Europese harmonisatie nog wat verder. En Van Hoepen evalueerde het onderzoek naar 'cultuur en externe verslaggeving'. Die evaluatie viel niet bijzonder positief uit:

- hoewel het aantal studies waarin de relatie tussen cultuur en financial accounting min of meer expliciet naar voren komt nog tamelijk beperkt is, '... kan men zich afvragen of verder onderzoek op dit terrein erg vruchtbaar is voor de verdere ontwikkeling van het vakgebied externe verslaggeving.'

- studies die trachten accounting systems te classificeren roepen de vraag op '... of het zinvol is nog veel verdere onderzoekinspanningen in deze richting te investeren. Ik kan me althans niet voorstellen.wat we er nog wijzer van kunnen worden.'

Wellicht komen deze conclusies in het artikel zelf niet zozeer als een verrassing, omdat de auteur zich al in het begin afvraagt '... of een studie naar verschillen in accounting systems veel waardevoller is dan een studie van de verschillende kleuren die vlinders op hun vleugels kunnen hebben.' Een bioloog zal van deze uitspraak verrast opkijken. Zijn hele wetenschap berust op classificatie. Darwin en Wallace streden om de verklaring van de flamboyante, en schijnbaar nutteloze kleuren die vlinders en pauwen konden aannemen. Die wetenschappelijke strijd heeft in de biologie nog decennia voortgeduurd. Het was één van de belangrijkste te verklaren anomalieën in de evolutietheorie.

Wel zinvol lijkt Van Hoepen een onderzoek naar de mogelijke relatie tussen welvaart en accounting systems: 'Eerder een taak voor economisten dunkt me dan de relatie tussen cultuurdimensies en accounting systems.' Nu wil het toeval dat ik ongeveer tezelfdertijd in het economistenblad ESB een soortgelijke relatie besprak, namelijk tussen het aantal accountants en de welvaart per land. ${ }^{2} U$ ziet deze relatie in onderstaande tabel weergegeven voor vijf Europese landen. Let vooral op de rangordes die tussen haakjes staan aangegeven:

\begin{tabular}{lcccc}
\hline & $\begin{array}{l}\text { Aantal accountants } \\
\text { (per mln. inw.) }\end{array}$ & $\begin{array}{l}\text { BNP per hoofd } \\
\text { (in ecu) }\end{array}$ \\
\hline Verenigd Koninkrijk & 2923 & $(1)$ & 12.363 & $(5)$ \\
België & 797 & $(2)$ & 12.941 & $(4)$ \\
Nederland & 406 & $(3)$ & 13.043 & $(3)$ \\
Frankrijk & 225 & $(4)$ & 14.479 & $(2)$ \\
Duitsland & 78 & $(5)$ & 16.667 & $(1)$ \\
\hline
\end{tabular}

Uiteraard is de keuze van bovenstaande viff landen geschied met het oog op een maximaal suggestief effect. Voor alle twaalf EG-lidstaten bedraagt de rangcorrelatie tussen het aantal accountants en het $B N P$ niet -1 , maar 0,0 .

$\mathrm{Nu}$ is hiermee natuurlijk niet aangetoond dat er geen verband zou kunnen zijn tussen welvaart per

Prof. Dr. H. Schreuder is directeur Planning en Ontwikkeling van DSM Kunststoffen. Hij is tevens hoogleraar Bedrijfseconomie aan de RU Limburg. In 1991-1992 was hij President van de European Accounting Association. 


\section{MAB}

land en de gekozen accounting systems. Ik heb althans altijd het gevoel gehad dat de Duitsers niet echt economisch geleden hebben onder het Massgeblichkeitsprinzip, om nog maar te zwijgen over de Zwitsers met hun merkwaardige vormen van reservering. Wellicht is het 'vrije markt'-kapitalisme van de VS en het VK niet altijd te prefereren boven het 'netwerk'-kapitalisme van Duitsland en Japan of het 'familie'-kapitalisme van Korea en Latijnse landen. Misschien moeten we wel meer dan de heersende Anglo-Amerikaanse opvattingen toestaan, aandacht besteden aan:

- winstinhouding

- supervisie door deskundige insiders

- relaties binnen industriële groepen, en

- nationaal industriebeleid.

Kortom: misschien zijn het wel de instituties die wij kiezen, die de basis voor onze welvaart vormen.
En misschien is die keuze van instituties niet geheel cultuurvrij. ${ }^{3}$

Voor wie het weten wil: de (multipele) correlatie tussen Hofstede's cultuurdimensies en de welvaart per land bedraagt $0,70.4$

\section{Noten}

1 Zie Helena Cronin, The Ant and the Peacock, Cambridge University Press, 1991.

2 John Flower, The Contribution of the Accountancy Profession of West Europe to the Development of the Economies of East Europe, Centre for Research in European Accounting, Brussel, 1992.

3 Zie bijvoorbeeld het rapport 'Scanning the Future' van het CPB.

4 G. Holstede, Culture's Consequences, Sage, 1984, p. 226 